\title{
Performance Analysis of AODV and OLSR protocol in Mobile Ad Hoc Network using NS3
}

Soumya S. ${ }^{1}$, Krishna Prasad K. ${ }^{2}$ \& Navin N. Bappalige ${ }^{3}$

${ }^{1}$ Research Scholar, College of Computer \& Information Sciences, Srinivas University, Mangalore, Karnataka, India and Faculty, Computer Science, Hira Women's College, Mangalore, Karnataka, India

OrcidID: 0002-5431-1977; E-mail: pksoumyaa@gmail.com

${ }^{2}$ Associate Professor \& Post-Doctoral Research Fellow, College of Computer \& Information

Sciences, Srinivas University, Mangalore, Karnataka, India

OrcidID: 0000-0001-5282-9038; E-mail: krishnaprasadkcci@srinivasuniversity.edu.in

${ }^{3}$ Associate Professor, Sahyadri College of Engineering \& Management, Mangalore

OrcidID: 0000-0003-1122-4897; E-mail: nbappalige@gmail.com

Area/Section: Computer Science \& Engineering.

Type of the Paper: Research Paper.

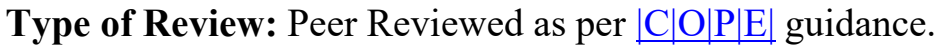

Indexed in: OpenAIRE.

DOI: http://doi.org/10.5281/zenodo.4384225

Google Scholar Citation: IJMTS.

\section{How to Cite this Paper:}

Soumya S., Krishna Prasad K. \& Navin N. Bappalige (2020). Performance Analysis of AODV and OLSR protocol in Mobile Ad Hoc Network using NS3. International Journal of Management, Technology, and Social Sciences (IJMTS), 5(2), 372-379. DOI: http://doi.org/10.5281/zenodo.4384225

International Journal of Management, Technology, and Social Sciences (IJMTS) A Refereed International Journal of Srinivas University, India.

(C) With Author.

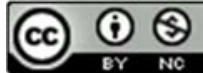

This work is licensed under a Creative Commons Attribution-Non-Commercial 4.0 International License subject to proper citation to the publication source of the work.

Disclaimer: The scholarly papers as reviewed and published by the Srinivas Publications (S.P.), India are the views and opinions of their respective authors and are not the views or opinions of the SP. The SP disclaims of any harm or loss caused due to the published content to any party.
\end{abstract}




\title{
Performance Analysis of AODV and OLSR protocol in Mobile Ad Hoc Network using NS3
}

\author{
Soumya S. ${ }^{1}$, Krishna Prasad K. ${ }^{2}$ \& Navin N. Bappalige ${ }^{3}$ \\ ${ }^{1}$ Research Scholar, College of Computer \& Information Sciences, Srinivas University, \\ Mangalore, Karnataka, India and Faculty, Computer Science, Hira Women's College, \\ Mangalore, Karnataka, India \\ OrcidID: 0002-5431-1977; E-mail: pksoumyaa@gmail.com \\ ${ }^{2}$ Associate Professor \& Post-Doctoral Research Fellow, College of Computer \& Information \\ Sciences, Srinivas University, Mangalore, Karnataka, India \\ OrcidID: 0000-0001-5282-9038; E-mail: krishnaprasadkcci@srinivasuniversity.edu.in \\ ${ }^{3}$ Associate Professor, Sahyadri College of Engineering \& Management, Mangalore \\ OrcidID: 0000-0003-1122-4897; E-mail: nbappalige@gmail.com
}

\begin{abstract}
Mobile Ad Hoc networks is a network in which energy is a main constraint and selection of a protocol that minimizes the energy usage is a key issue. Mobile Ad hoc network communicates with other nodes, without the help of base station and Communication is possible by forwarding a data unit consisting of control information and user data known as packets from one node to other. Furthermore, another key issue in mobile ad hoc networks is routing since the nodes are in mobility and tend to change the paths and move out of the network. The evaluation of energy efficient routing protocols can be effectively performed using NS3. Three types of routing protocols can be seen, Reactive, Proactive and Hybrid and in this paper, AODV a reactive protocol and OLSR a proactive protocol is compared and Delivery ratio of packets, Packet Loss and count of packets received are evaluated to analyze the energy efficiency of protocols based on these metrics.
\end{abstract}

Keywords: Routing protocols, AODV, OLSR, PDR, Throughput, Energy.

\section{INTRODUCTION :}

Mobile Ad Hoc Network is a dynamic, and self-configurable network mainly used for specific tasks, where fixed base station is unavailable [1]. Mobile Ad Hoc Network can be used in tasks such as Military Operations [2], natural disasters, or any mission-specific purposes. As mobile ad hoc network is not based on fixed infrastructure [3], the path selection from source to destination is dynamically discovered, and network nodes communicate with each other by redirecting the packets to the next node, only if the next node is within the network coverage area [4]. So, the selection of the best itineraries to the destination from the source is the key issue since the nodes in the network are in mobility and can move away from its neighboring nodes [5] at any point in time. A new path is reestablished during the unavailability of nodes for forwarding packets [6]. Another main problem in the mobile ad hoc network is the energy use of each node in network communication [7] since nodes in ad hoc networks rely on the battery and battery is a constraint in MANETs [8]. So, if the energy efficient protocols are used energy consumption of the nodes can be minimized [9] for the route discovery. Three types of routing protocols are available for MANETs, including proactive protocols, reactive and hybrid protocols [10]. The constructive protocol initially performs the route discovery and later routes during the transmission are updated [11]. In the reactive protocol, route discovery is performed at each node while the packets are forwarded [12]. Furthermore, hybrid protocols use the Proactive as well as reactive protocol characteristics. In this paper, the Optimized Link State Routing (OLSR) Protocol and the Ad Hoc On-Demand Distance Vector (AODV) reactive protocol are compared and evaluated to conclude that in other Parameters such as the transmission ratio of packets, loss of packets and count 
of received packets, this protocol can reduce energy consumption and performance evaluation is obtained.

\section{RELATED WORKS :}

A Mobile Ad Hoc Network can be analysed using several Simulators, many researchers have chosen and analysed MANET routing protocols using Network Simulator 3, and evaluated the efficiency and drawbacks of routing protocols based on different scenarios and quantitative metrics, some of the analysis performed during the past decade are given in Table 1.

Table 1: Review of Performance analysis in AODV and OLSR protocols.

\begin{tabular}{|c|c|c|c|}
\hline S. No. & Simulation Analysis & Focus & Reference \\
\hline 1 & $\begin{array}{l}\text { A modified protocol ESPR- } \\
\text { OLSR is evaluated in NS3. }\end{array}$ & $\begin{array}{l}\text { Distance calculation is } \\
\text { performed between the } \\
\text { nodes to reduce overhead. }\end{array}$ & $\begin{array}{l}\text { K. Prabu } \\
{[1]}\end{array}$ \\
\hline 2 & $\begin{array}{l}\text { OLSR and AODV protocols } \\
\text { are evaluated using NS3. }\end{array}$ & $\begin{array}{l}\text { End to End Delay, Packet, } \\
\text { and several quantitative } \\
\text { metrics are analyzed. }\end{array}$ & $\begin{array}{l}\text { Rakesh Kumar Jha } \\
{[3]}\end{array}$ \\
\hline 3 & $\begin{array}{l}\text { A protocol called square } \\
\text { cluster-based routing protocol } \\
\text { is evaluated using NS3. }\end{array}$ & $\begin{array}{l}\text { Non-overlapping clusters } \\
\text { are selected and evaluated } \\
\text { using different metrics. }\end{array}$ & $\begin{array}{l}\text { Salma S. Mohamed } \\
{[4]}\end{array}$ \\
\hline 4 & $\begin{array}{l}\text { Buffer Enabled Ad hoc On- } \\
\text { demand Multipath Distance } \\
\text { Vector } \\
\text { algorithm is evaluated using } \\
\text { NS3. }\end{array}$ & $\begin{array}{l}\text { Distributes the load over a } \\
\text { single node among other } \\
\text { nodes. }\end{array}$ & $\begin{array}{l}\text { Banerjee, A } \\
{[5]}\end{array}$ \\
\hline 5 & $\begin{array}{l}\text { The node disjoint energy- } \\
\text { efficient multipath routing } \\
\text { (NDE-MR) is evaluated using } \\
\text { NS3. }\end{array}$ & $\begin{array}{l}\text { This method proved to be } \\
\text { energy efficient and } \\
\text { remarkably decreased } \\
\text { energy consumption. }\end{array}$ & $\begin{array}{l}\text { Anita, R } \\
\text { [6] }\end{array}$ \\
\hline 6 & $\begin{array}{l}\text { Environs Aware Neighbor- } \\
\text { knowledge based Broadcasting } \\
\text { (EANKBB)using NS2. }\end{array}$ & $\begin{array}{l}\text { Various metrics like } \\
\text { throughput, bandwidth are } \\
\text { analysed. }\end{array}$ & $\begin{array}{l}\text { Banumathi } \\
\text { [7] }\end{array}$ \\
\hline 7 & $\begin{array}{l}\text { Adaptive-gossiping routing } \\
\text { algorithm is evaluated using } \\
\text { NS3. }\end{array}$ & $\begin{array}{l}\text { Adaptive-gossiping is } \\
\text { compared with flooding and } \\
\text { static gossiping algorithms. }\end{array}$ & $\begin{array}{l}\text { Lee, A } \\
{[9]}\end{array}$ \\
\hline 8 & $\begin{array}{l}\text { Energy efficient probabilistic } \\
\text { broadcasting (EEPB) is the } \\
\text { proposed algorithm is } \\
\text { evaluated using NS3. }\end{array}$ & $\begin{array}{l}\text { Route Requests are sent on } \\
\text { the basis of the remining } \\
\text { energy in the nodes }\end{array}$ & $\begin{array}{l}\text { Kumar, S } \\
{[10]}\end{array}$ \\
\hline 9 & $\begin{array}{l}\text { Reference Point } \text { Group } \\
\text { Mobility model is evaluated } \\
\text { using NS3. }\end{array}$ & $\begin{array}{l}\text { Link stability analysis } \\
\text { based on the maximum } \\
\text { duration of link stability in } \\
\text { DSDV and OLSR } \\
\text { protocols. }\end{array}$ & $\begin{array}{l}\text { Oo, M } \\
{[11]}\end{array}$ \\
\hline 10 & $\begin{array}{l}\text { Performance evaluation of } \\
\text { DSR and AODV using } \\
\text { simulator, }\end{array}$ & $\begin{array}{l}\text { Energy Consumption and } \\
\text { incremental cost, }\end{array}$ & $\begin{array}{l}\text { Feeney, L } \\
\text { [12] }\end{array}$ \\
\hline 11 & $\begin{array}{l}\text { Enhanced distance based } \\
\text { (EDB) algorithm is evaluated } \\
\text { using NS3. }\end{array}$ & $\begin{array}{l}\text { The behavior of the } \\
\text { protocol and coverage is } \\
\text { evaluated and enhanced. }\end{array}$ & $\begin{array}{l}\text { Ruiz } \\
{[14]}\end{array}$ \\
\hline 12 & $\begin{array}{l}\text { Load the Balanced Termite } \\
\text { method is evaluated using } \\
\text { simulator. }\end{array}$ & $\begin{array}{l}\text { Finding the reliable and } \\
\text { strong path for the } \\
\text { transmission. }\end{array}$ & $\begin{array}{l}\text { Kiran, M } \\
{[15]}\end{array}$ \\
\hline
\end{tabular}




\section{METHODS :}

The assessment is performed using energy-efficient protocols such as AODV and OLSR, and the study and comparison of various quantitative metrics is conducted.

$A O D V$

A reactive protocol for ad hoc networks is the Ad Hoc On Demand Distance Vector (AODV) and this protocol preserves a routing table containing the entries required to find the routes [16]. The next node, sequence number, and hop count are the three key entries that can be used in the AODV protocol routing table [17]. The AODV protocol distinguishes routes from source to destination by broadcasting [18], requesting a response message to all of its neighboring nodes [19], and seeks a correct route from source to destination. After the broadcasting of RREQ messages using the AODV protocol, there is the possibility of discovery of more than one routes [20], in such cases the routes with the maximum sequence number are selected [21] for data transmission. Whenever a new route node is chosen as the source-to-destination route, the sequence number is modified [22]. The selection of new node for the route discovery happens when a node fails or drops out of a network [23].

\section{OLSR}

The Optimized Link State Routing Protocol is a proactive Mobile ad hoc network protocol and it is a table-driven protocol [24]. The OSLR protocol discovers its route from source to destination by regular exchange of topology information with its neighboring nodes [25]. Multi Point Relays (MPR) are a group of nodes chosen by the OLSR [26] control traffic exchange protocol. The MPR nodes are neighbour nodes of the source node, which has initiated route discovery [27]. The selected MPRs are only responsible for flooding the control traffic to the neighboring nodes [28], which further reduces the number of transmissions [29]. Once the MPRs discovers the shortest path, the Link state is exchanged periodically among MPRs [30].

\section{RESULTS AND DISCUSSIONS :}

Network Simulator 3 (NS3) is an open-source simulator which makes it possible to simulate with discrete node count. In the proposed work simulation, 50 nodes are simulated, and the number of sinks is 10, propagation model used is Constant Speed Propagation Delay, propagation loss model used is Friis, Position Allocator is Random Rectangular Position Allocator, Mac is Adhoc Wifi Mac, Mac Standard is $802.11 \mathrm{~B}$, Bps is $2 \mathrm{Kpbs}$, Total simulation time is 120 seconds, Node pause time is 0 . Protocol used in this proposed work is AODV and OLSR and both the protocols are evaluated on the basis of the above-mentioned scenarios.

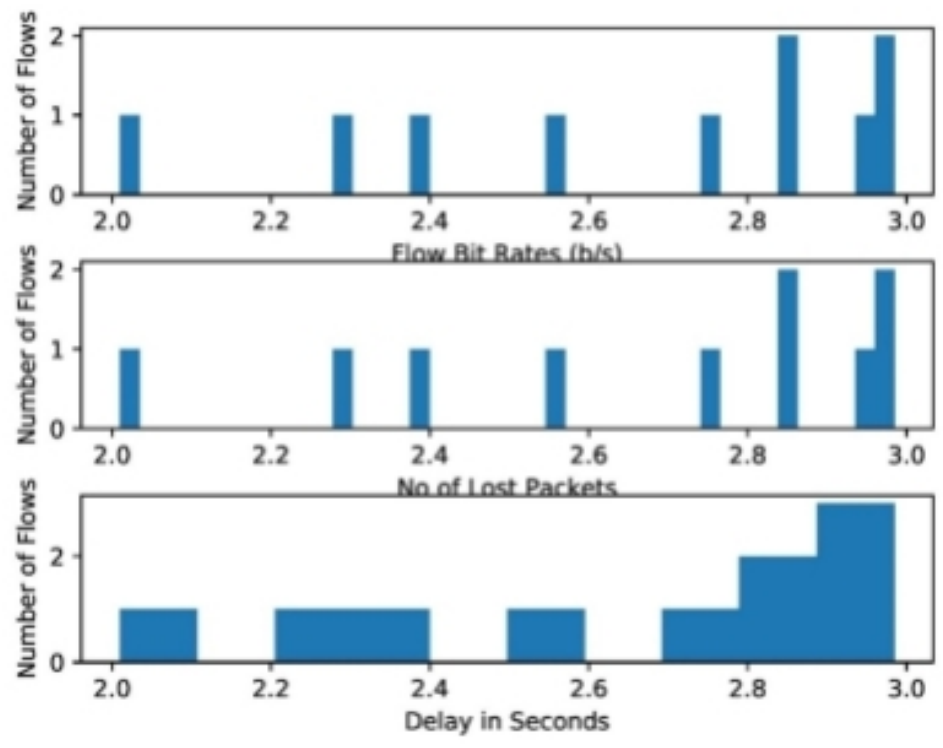

Fig. 1: No of Lost Packets and Delay in seconds in AODV protocol. 
In the simulation initially the protocol AODV is analysed for Bit rate flow, the number of packets lost and lag in seconds to receive the packets. Figure 1 shows the Bit rate flow, the number of packets lost and lag in seconds to receive packets based on total flow count. In this simulation total flow count is 2 and flow bit rate is good in bits per second in AODV. Figure 1 also analyses the number of lost packets during the transmission. Furthermore, delay in seconds to receive the packets. The delay in the packet increases at the end of transmission.

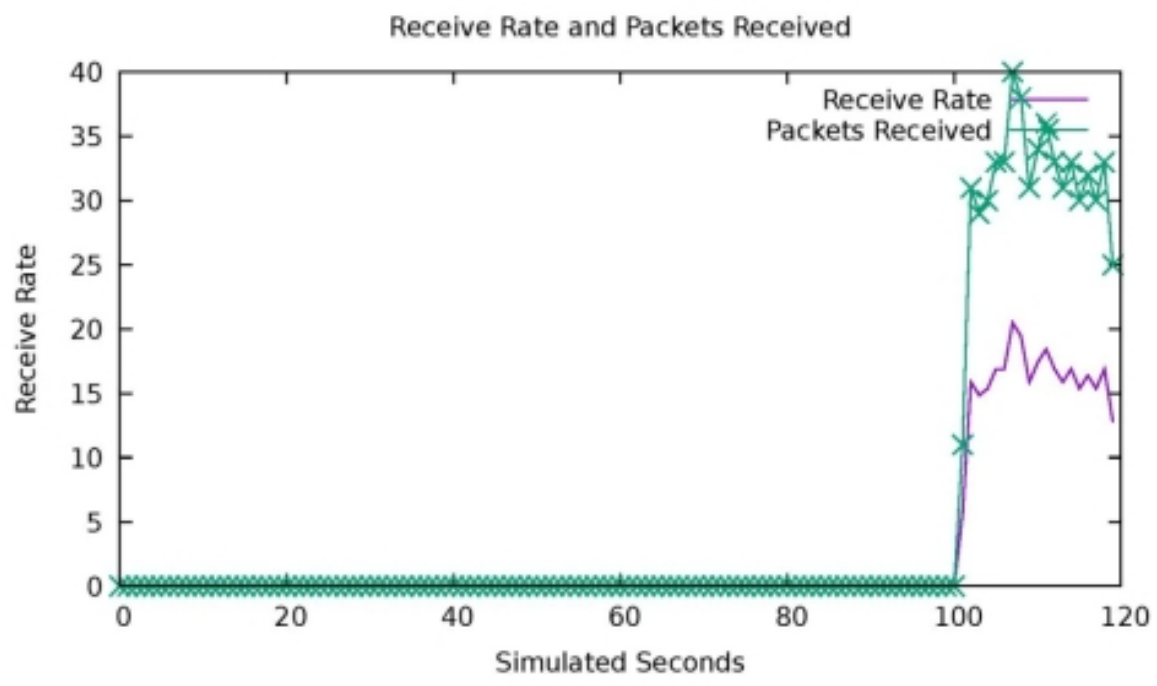

Fig. 2: Rate of received packets and Packets Received analysis in AODV protocol.

Figure 2 shows the rate of received packets and Packets Received in AODV protocol. The receive rate of AODV protocol is stable during initial 100 seconds, and a sudden raise is visible in the diagram at the end in the simulation, which shows that the protocol requires 100 -second duration to transmit the packets and then it is received at the destination.

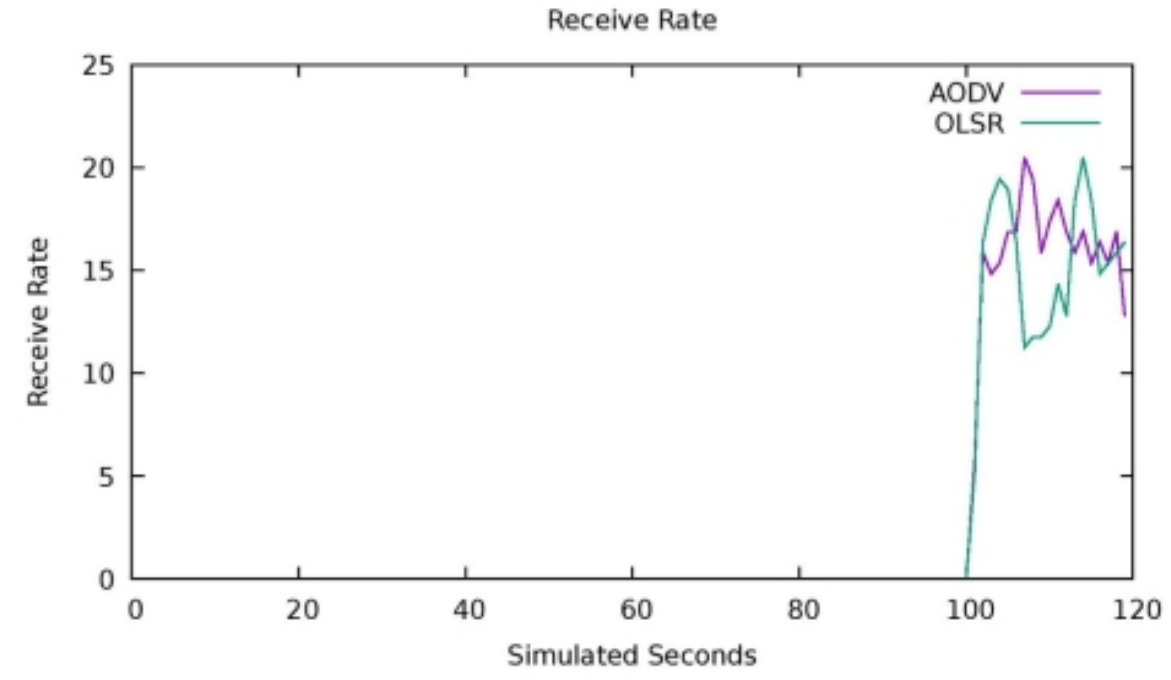

Fig. 3: Comparison of AODV and OLSR protocol based on Receive Rate.

Figure 3 shows the comparative analysis of AODV and OLSR protocols on receive rate. The received rate of both protocols is stable. 


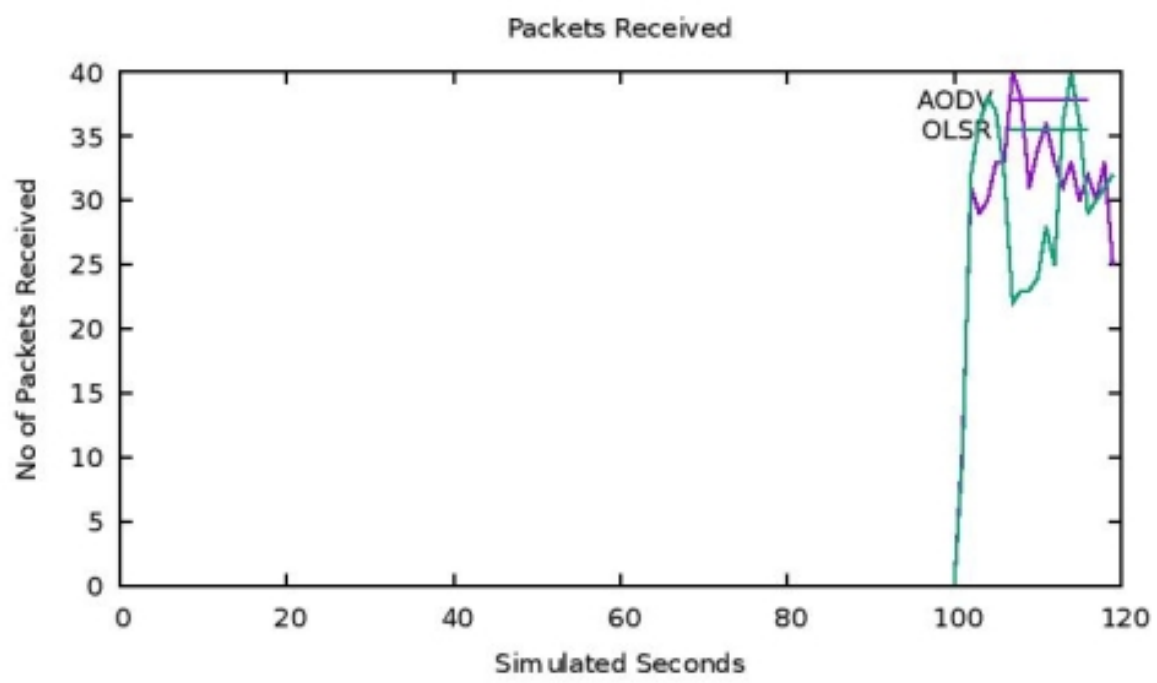

Fig. 4: Comparison of AODV and OLSR protocol based on No. of packets received.

Demonstration of a comparative analysis focused on the received packets count under the protocols AODV and OLSR are shown in Fig.4. In comparison to the OLSR protocol, the received packets count using AODV is high.

\section{CONCLUSION :}

Performance can be analysed from the NS3 simulation performed on AODV and OLSR that receives the rate of OLSR decreases along with the time. Furthermore, the number of packets received in AODV is highly compared to OLSR. So, when time elapses AODV can do the maximum usage of residual energy and Elevates the lifespan of the network and reduces the loss of packets. The evaluation of both the protocol is performed by changing the simulation scenarios such as the node count, Period of simulation and flow count. Furthermore, it is evaluated that AODV has better performance than OLSR. The future work can include simulation metrics such as efficiency, delay and further evaluation can be conducted.

\section{REFERENCES :}

[1] Prabu, K., \& Subramani, A. (2014). Energy efficient routing in MANET through edge node selection using ESPR algorithm. International Journal of Mobile Network Design and Innovation, 5(3), 166-175.

[2] Cervera, G., Barbeau, M., Garcia-Alfaro, J., \& Kranakis, E. (2013). A multipath routing strategy to prevent flooding disruption attacks in link state routing protocols for MANETs. Journal of Network and Computer Applications, 36(2), 744-755.

[3] Jha, R. K., \& Kharga, P. (2015). A comparative performance analysis of routing protocols in MANET using NS3 simulator. International Journal of Computer Network and Information Security, 7(4), 62-68.

[4] Mohamed, S. S., Abd-Elfattah, A. I., \& Mohamed, M. A. (2020). A new clustering technique based on replication for MANET routing protocols. TELKOMNIKA, 18(6), 3339-3345.

[5] Robinson, Y. H., Balaji, S., \& Julie, E. G. (2019). Design of a buffer enabled ad hoc on-demand multipath distance vector routing protocol for improving throughput in mobile ad hoc networks. Wireless Personal Communications, 106(4), 2053-2078.

[6] Anita, R. (2017). Joint cost and secured node disjoint energy efficient multipath routing in mobile ad hoc network. Wireless Networks, 23(7), 2307-2316. 
[7] Banumathi, J., \& Kanthavel, R. (2018). Node Failure Aware Broadcasting Mechanism in Mobile Adhoc Network Environment. Programming and Computer Software, 44(6), 371-380.

[8] Nikaein, N., \& Bonnet, C. (2004). Topology management for improving routing and network performances in mobile ad hoc networks. Mobile Networks and Applications, 9(6), 583-594.

[9] Lee, A., \& Ra, I. (2015). Network resource efficient routing in mobile ad hoc wireless networks. Telecommunication Systems, 60(2), 215-223.

[10] Kumar, S., \& Mehfuz, S. (2017). Energy Efficient Probabilistic Broadcasting for Mobile Ad-Hoc Network. Journal of the Institution of engineers (India): Series B, 98(3), 289-294.

[11] Oo, M. Z., \& Othman, M. (2012). Analytical studies of interaction between mobility models and single-multi paths routing protocols in mobile ad hoc networks. Wireless Personal Communications, 64(2), 379-402.

[12] Feeney, L. M. (2001). An energy consumption model for performance analysis of routing protocols for mobile ad hoc networks. Mobile Networks and applications, 6(3), 239-249.

[13] Schweitzer, N., Stulman, A., Hirst, T., Margalit, R. D., \& Shabtai, A. (2019). Network bottlenecks in OLSR based ad-hoc networks. Ad Hoc Networks, 88(1), 36-54.

[14] Ruiz, P., Dorronsoro, B., Valentini, G., Pinel, F., \& Bouvry, P. (2012). Optimisation of the enhanced distance based broadcasting protocol for manets. The journal of Supercomputing, 62(3), 1213-1240.

[15] Kiran, M., \& Reddy, G. R. M. (2014). Design and evaluation of load balanced termite: A novel load aware bio inspired routing protocol for mobile ad hoc network. Wireless personal communications, 75(4), 2053-2071.

[16] Pandey, A., \& Srivastava, A. (2013). Performance Evaluation of MANET through NS2 Simulation. International Journal of Electronic and Electrical Engineering, 7(1), 25-30.

[17] Gupta, D., \& Gujral, R. K. (2014). Simulation of Different Routing Protocols in MANET Using NS2. International Journal of Scientific and Research Publications, 4(8), 1-5.

[18] Zemrane, H., Baddi, Y., \& Hasbi, A. (2019). Mobile AdHoc networks for Intelligent Transportation System: Comparative Analysis of the Routing protocols. Procedia Computer Science, 1609(1), 758-765.

[19] Kumar, K., \& Singh, V. P. (2014). Power consumption-based simulation model for mobile ad-hoc network. Wireless personal communications, 77(2), 1437-1448.

[20] Raheel, M. S., \& Raad, R. (2020). Energy efficient technique for P2P multisource video streaming in mobile ad hoc networks to improve QoE. Peer-to-Peer Networking and Applications, 13(1), 219-242.

[21] Sekar, P. C., \& Mangalam, H. (2019). Third generation memetic optimization technique for energy efficient routing stability and load balancing in MANET. Cluster Computing, 22(5), 11941-11948.

[22] Anand, M., \& Sasikala, T. (2019). Efficient energy optimization in mobile ad hoc network (MANET) using better-quality AODV protocol. Cluster Computing, 22(5), 12681-12687.

[23] Aruna, R., Subramanian, R., Sengottuvelan, P., \& Shanthini, J. (2019). Optimized energy efficient route assigning method using related node discovery algorithm in MANET. Cluster Computing, 22(1), 469-479.

[24] Venu, S., \& Rahman, A. M. Z. (2019). Energy and cluster based efficient routing for broadcasting in mobile ad hoc networks. Cluster Computing, 22(1), 661-671.

[25] Deepa, J., \& Sutha, J. (2019). A new energy based power aware routing method for MANETs. Cluster Computing, 22(6), 13317-13324.

[26] Tavizi, A., \& Ghaffari, A. (2018). Tree-based reliable and energy-aware multicast routing protocol for mobile ad hoc networks. The Journal of Supercomputing, 74(11), 6310-6332. 
[27] Kumar, S. S., Manimegalai, P., \& Karthik, S. (2019). A rough set calibration scheme for energy effective routing protocol in mobile ad hoc networks. Cluster Computing, 22(6), 13957-13963.

[28] Chizari, H., Hosseini, M., Salleh, S., Abd Razak, S., \& Abdullah, A. H. (2012). EF-MPR, a new energy efficient multi-point relay selection algorithm for MANET. The Journal of Supercomputing, 59(2), 744-761.

[29] Costagliola, N., López, P. G., Oliviero, F., \& Romano, S. P. (2012). Energy-and delay-efficient routing in mobile ad hoc networks. Mobile Networks and Applications, 17(2), 281-297.

[30] Chaudhry, R., \& Tapaswi, S. (2019). Bio-inspired energy conserving adaptive power and rate control in MANET. Computing, 101(11),1633-1659.

$* * * * * * * * * * * * *$ 